\title{
National differences for thirty-seven nations in extraversion, neuroticism, psychoticism and economic, demographic and other correlates
}

\author{
Richard Lynn and Terence Martin \\ Psychology Department, University of Ulster, Coleraine BT52 ISA. Northern Ireland
}

(Received 19 November 1994)

\begin{abstract}
Summary - National mean scores for extraversion, neuroticism and psychoticism were obtained for a large sample of nations together with national means for the work ethic and competitiveness. These data were intercorrelated with additional variables including per capita incomes and national prevalence rates of suicide, homicide and alcoholism. The results showed a number of significant relationships. Factor analysis revealed the presence of three factors which were interpreted as extraversion, neuroticism and psychoticism. The contribution of questionnaire data and demographic indices as methods for measuring national differences in personality is discussed
\end{abstract}

\section{INTRODUCTION}

Previous research concerning the measurement of national differences in personality has generally been pursued through the use of either questionnaire studies or from demographic indices. The general objective of this research has been to ascertain whether there are differences between nations in personality traits and whether these have economic and demographic correlates.

Cross-cultural personality research has been much aided by the development of the Eysenck Personality Questionnaire (EPQ), first standardized in England (Eysenck \& Eysenck, 1975) and constructed to measure the three major dimensions of $\mathrm{E}$ (extraversion vs introversion), $\mathrm{N}$ (neuroticism vs emotional stability) and $\mathbf{P}$ (psychoticism vs ego control). The EPQ has been standardized in a number of countries and the earlier research has been summarized by Barrett and Eysenck (1984). The primary aims of these cross-cultural studies have been threefold: (1) to establish the presence of the major dimensions of $\mathrm{E}, \mathrm{N}$ and $\mathrm{P}$ in other cultures; (2) to provide a valid measuring instrument for use in the country under consideration; and (3) to allow for the comparison of norms on these dimensions between different countries.

Although the Eysenckian approach has been dominant in this field, a variety of additional questionnaire studies have examined national differences in personality traits. In one such study, Hofstede (1976) obtained mean scores on neuroticism (anxiety) in 40 different nations on the basis of a single-item inventory consisting of answers to the question. "How often do you feel nervous or tense at work?". The responses were scored on a five-point scale ( $1=$ always, $5=$ never $)$. In spite of its obvious shortness evidence suggests that the national mean scores obtained by Hofstede correlate with other measures of anxiety or neuroticism in the same countries (Lynn, 1982).

The use of demographic indices in the assessment of national differences in personality was first adopted by Lynn (1971) to measure anxiety levels in 18 industrialized nations. Taking prevalence rates and consumption figures of a range of national demographic and epidemiological phenomena which are correlates of anxiety or neuroticism among individuals, it was shown that there is a sizeable general factor in the intercorrelation of these variables, which is interpretable as the anxiety curve of the population. Extending this theory Lynn and Hampson (1975) proposed that a substantial proportion of the variance in a number of demographic phenomena could be explained in terms of national differences in neuroticism and extraversion. Twelve demographic variables were used, eight of which (national rates of suicide, alcoholism, accidents, chronic psychosis, coronary heart disease, and the per capita consumption of calories, caffeine and cigarettes) were primarily measures of neuroticism. The remaining four variables were primarily measures of extraversion (national rates of crime, murder, illegitimacy and divorce).

Further extensive normative data for national differences in work attitudes, including the work ethic and competitiveness have been reported for 41 nations in Lynn (1991).

There are therefore four types of national data which could potentially be integrated. namely the three personality dimensions of extraversion, neuroticism and psychoticism; demographic data such as national rates of suicide, accidents and so on; economic data such as per capita income; and work attitude data. Our purpose in this paper is to present normative data for a number of these phenomena and examine how far interpretable relationships exist between them.

\section{METHOD}

The choice of nations to be included in this study was determined by the availability of normative data for the personality dimensions of extraversion $(E)$, neuroticism $(N)$ and psychoticism $(P)$. Our starting point was the compilation of means for 24 nations on $E, N$ and $P$ presented by Barrett and Eysenck (1984). There is a problem in calculating national means for $E$, $\mathrm{N}$ and $\mathrm{P}$ because the scales consist of different numbers of items in different countries. The reason for this is that the questionnaires were administered in the respective countries, factored, and only those questions loading on the appropriate factors were used for the final versions. Typically this involved eliminating two or three questions from each scale. Since the scales were shortened, the means necessarily fell. Barrett and Eysenck overcame this problem by prorating all scales up to 30 items and we have adopted the same procedure.

In the years since the Barrett and Eysenck compilation of $\mathrm{E}, \mathrm{N}$ and $\mathrm{P}$ data for 24 countries, normative data for a further 13 countries has been published. The references for these later studies are shown in the Appendix. 


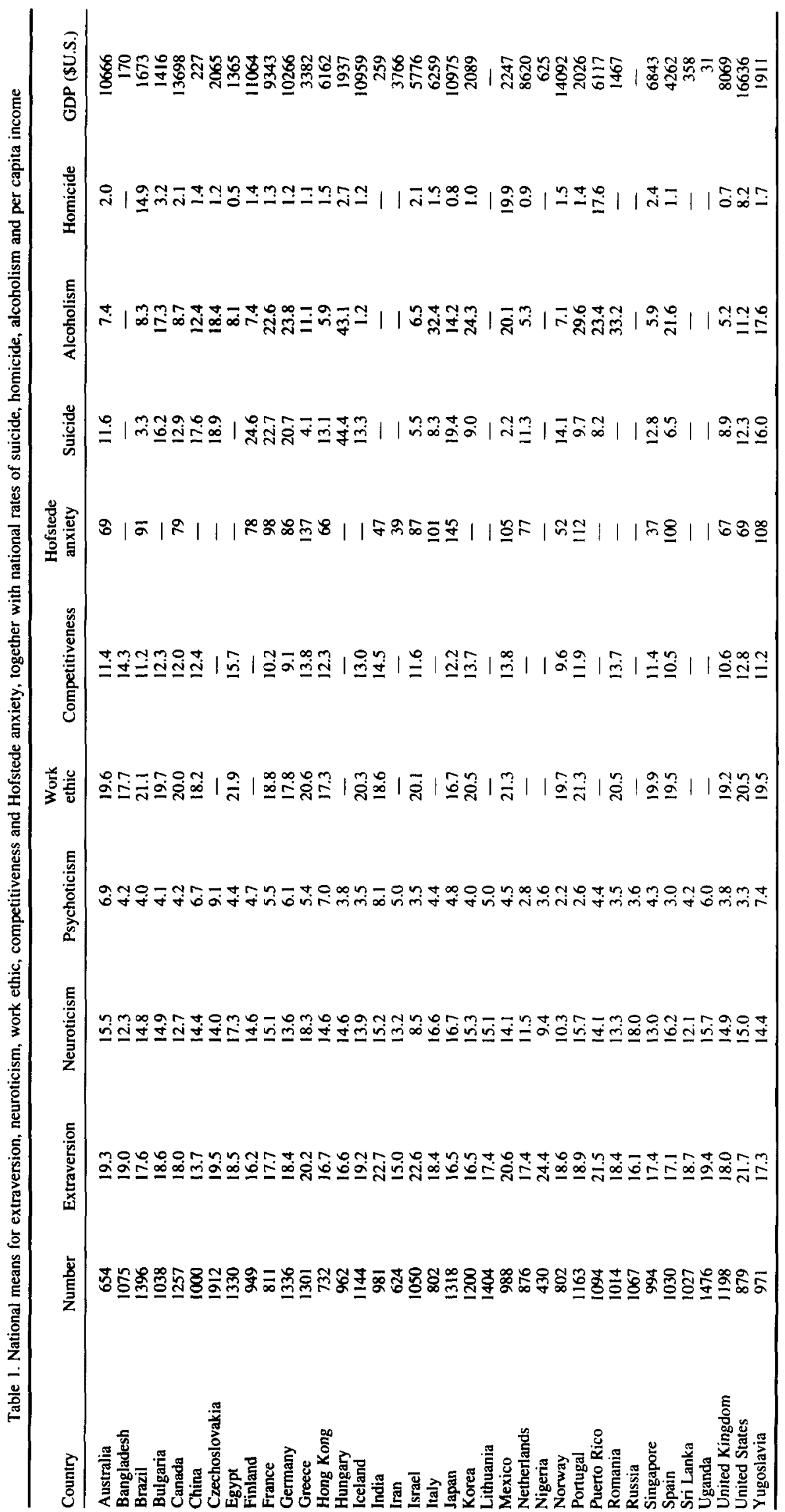


Table 2. Correlation matrix of 37 nation sample (decimal points omitted)

\begin{tabular}{|c|c|c|c|c|c|c|c|c|c|}
\hline Measures & 1 & 2 & 3 & 4 & 5 & 6 & 7 & 8 & 9 \\
\hline 1. Extraversion & & & & & & & & & \\
\hline 2. Neuroticism & $-32 *$ & & & & & & & & \\
\hline 3. Psychoticism & -03 & 23 & & & & & & & \\
\hline 4. Work ethic & 32 & 08 & $-48^{*}$ & & & & & & \\
\hline 5. Competitiveness & 25 & 31 & 10 & 27 & & & & & \\
\hline 6. Suicide & $-44^{*}$ & 04 & 18 & $-70^{* *}$ & -40 & & & & \\
\hline 7. Alcoholism & -06 & 25 & -03 & 06 & -01 & $39^{*}$ & & & \\
\hline 8. Hofstede anxiety & 02 & $50^{*}$ & -05 & 01 & 14 & -11 & $52^{*}$ & & \\
\hline 9. Homicide & $42 *$ & -05 & -11 & 40 & 17 & -35 & 10 & 05 & \\
\hline 10. Per Capila Income & -03 & -08 & -23 & -15 & $-48^{*}$ & 07 & $-42^{*}$ & -17 & -13 \\
\hline
\end{tabular}

$* P<0.05 ; * * P<0.01$.

Our first step has therefore been to integrate the results for the 13 additional nations with those of the previous 24 nations. The entire set of data, including the number of $S$ s in each national sample for the total of 37 nations is presented in Table 1. The table also gives national means (available for 25 countries) for the work ethic and competitiveness obtained by Lynn (1991), and anxiety scores (available for 22 countries) gathered by Hofstede (1976).

Also included in our study were national rates of suicide (number of deaths per 100,000 population), homicide (number of deaths per 100,000 population) and alcoholism (number of deaths from liver cirrhosis per 100,000 population), together with national per capita income, expressed as the per capita gross domestic product. These data, which are for 1985 or the nearest available year and are taken from the United Nations Demographic and Accounts Statistics Yearbooks, also appear in Table 1.

All of the variables included in this study were intercorrelated in order to identify relationships between them across nations. This was followed by a factor analysis using SPSSX with a principal components extraction and a varimax rotation.

\section{RESUI.TS}

Table 2 presents the correlation matrix containing the Pearson product moment coefficients across nations. A number of significant results are present. Neuroticism is significantly correlated with Hofstede anxiety scores $(r=0.50, P<0.05)$. Hofstede anxiety is also significantly correlated with alcoholism $(r=0.52, P<0.05)$. There is a significant negative correlation between psychoticism and work ethic $(r=-0.48, P<0.05)$. Per capita income is significantly negatively correlated with competitiveness $(r=-0.48, P<0.05)$.

The results of the factor analysis are presented in Table 3 . Three factors were present with eigenvalues exceeding unity. We interpret these as extraversion (factor 1), neuroticism (factor 2) and psychoticism (factor 3) and consider these interpretations in the discussion section.

\section{DISCUSSION}

The sample of nations featured in the current study together with the diversity of variables involved, represented an ambitious large-scale correlational exercise that succeeded in uncovering a number of interesting associations and discounting a number of others.

The significant relationship between neuroticism and Hofstede's measure of national anxiety provides further evidence for the validity of these scales. Hofstede (1980) identified a personality dimension of "uncertainty avoidance", which refers to the extent to which people feel threatened by ambiguous situations. This basic personality dimension has been found to be highly significantly correlated with various measures of anxiety and neuroticism, including that identified by Lynn and Hampson (1975) in their study of 18 industrialized nations.

The positive direction of the relationship between neuroticism and alcoholism across nations is in keeping with previous research (Lynn \& Hampson, 1977). Similarly, the positive association between neuroticism and suicide supports previous work which has suggested that a high national suicide rate should be a function of a high national level of neuroticism (Lynn, 1982).

However, the coefficients obtained on these relationships in this study were weak and failed to reach significance.

The most interesting result concerning psychoticism involved the significant negative association with work ethic and supports previous research which has found the former to be connected with a rejection of social, economic and moral conservatism (Furnham, 1987).

There is a substantial negative correlation between competitiveness and national per capita income, suggesting that poor people value money more than the affluent.

Table 3. Varimax analysis of measures across nations

\begin{tabular}{lrrr}
\hline & Factor 1 & Factor 2 & Factor 3 \\
\hline Extraversion & 65 & -18 & -24 \\
Neuroticism & -03 & 49 & 68 \\
Psychoticism & -32 & -03 & 74 \\
Work ethic & 82 & 14 & -35 \\
Competitiveness & 69 & 06 & 56 \\
Suicide & -90 & -04 & 03 \\
Alcoholism & -18 & 88 & -20 \\
Homicide & 70 & 10 & 01 \\
Hofstede anxiety & 08 & 76 & 37 \\
Per capita income & -39 & -59 & -17 \\
\hline
\end{tabular}


We turn finally to the result of the factor analysis. We suggest that the three factors should be interpreted as extraversion, neuroticism and psychoticism, respectively. The first factor is interpreted as extraversion because of its loading of 0.65 . It has a high loading for homicide and competitiveness, as would probably be expected. The high loadings of the work ethic and the negative loading of suicide are less easy to explain. Factor 2 is interpreted as neuroticism which loads 0.49 on the factor, together with Hofstede anxiety scores $(0.76)$ and liver cirrhosis $(0.88)$ as a measure of alcoholism, interpretable as a function of anxiety because of the well-known properties of alcohol as an anxiety reducer. Notice that per capita income, measured by GDP, has a substantial negative loading on the factor of -0.59 , indicating that countries with low standards of living have high levels of neuroticism. The interpretation suggested is that poverty tends to be stressful and raises the level of neuroticism in poor countries. The result confirms the conclusion reached in Lynn (1991) on the basis of other kinds of evidence. Factor 3 is interpreted as psychoticism, which loads 0.74 on the factor. The loading of 0.56 of competitiveness is probably to be expected because of the aggressive component in psychoticism. The negative loading of work ethic of -0.35 is interpretable as due to the generally poor socialization component of psychoticism, of which a low work ethic is itself a component. The loading of 0.68 of neuroticism on this factor detracts from the clarity of the interpretation. Nevertheless, taking results of the factor analysis as a whole, we consider that they are reasonably interpreted as indicating the presence of differing values of the three personality dimensions across countries and of work values like competitiveness and the work ethic and demographic phenomena like suicide and alcoholism as expressions of these values.

\section{REFERENCES}

Barrett, P. \& Eysenck, S. B. G. (1984). The assessment of personality factors across 25 countries. Personality and Individual Differences, 5, 615-632.

Eysenck, H. J. \& Eysenck, S. B. G. (1975). Manual of the Eysenck Personality Questionnaire. London: Hodder \& Stoughton. Eysenck, H. J. \& Eysenck, S. B. G. (1976). Psychoticism as a dimension of personality. London: Hodder \& Stoughton. Eysenck, M. (1982). Attention and arousal, cognition and performance. Berlin: Springer.

Eysenck, S. B. G. (1983). One approach to cross-cultural studies of personality. Australian Journal of Psychology, 35, $381-391$.

Furnham, A. (1984). Many sides of the coin: The psychology of money usage. Personality and Individual Differences, 5 , 501-509.

Furnham, A. (1987). Predicting protestant work ethic beliefs. European Journal of Personality, 1, 93-106.

Hofstede, G. (1976). Nationality and organisational stress. Brussels: European Institute for Advanced Studies in Management.

Hofstede, G. (1980). Culture's consequences: International differences in work-related values. London: Sage.

Lynn, R. (1971). Personality and national character. Oxford: Pergamon Press.

Lynn, R. (1982). National differences in anxiety and extraversion. Progress in Experimental Personality Research, 11, 213-258.

Lynn, R. (1991). The secret of the miracle economy. London: The Social Affairs Unit.

Lynn, R. \& Hampson, S. L. (1975). National differences in extraversion and neuroticism. British Journal of Social and Clinical Psychology, 14, 223-240.

Lynn, R. \& Hampson, S. L. (1977). Fluctuations in national levels of neuroticism and extraversion, 1935-1970. British Journal of Social and Clinical Psychology, 16, 131-138.

\section{APPENDIX}

\section{Studies Carried Out Since Barrett and Eysenck (1984)}

Eysenck, S. B. G. (1985). Confronti transcultusali fra le personalita di soggetti italiani continentali, siciliani e inglesi. Bolletino di Psicologia Applicato, $176,11-16$.

Eysenck, S. B. G., Baban, A., Derevenco, P. \& Pitariu, H. (1989). A cross-cultural study of personality: Romanian and English adults. Revue Roumaine de Psychologie, 33, 75-80.

Eysenck, S. B. G., Barrett, P. T. \& Barnes, G. E. (1993). A cross-cultural study of personality: Canada and England. Personality and Individual Differences, 14, 1-10.

Eysenck, S. B. G., Barrett, P. T., Spielberger, C., Evans, F. J. \& Eysenck, H. J. (1986). Cross-cultural comparisons of personality dimensions: England and America. Personality and Individual Differences, 7, 209-214.

Eysenck, S. B. G. \& Cantu, M. A. L. (1989). Un estudio transcultural de la personalidad en adultus mexicanos e ingleses. Salud mental, 12, 14-20.

Eysenck, S. B. G. \& Haapasalo, J. (1989). Cross-cultural comparisons of personality: Finland and England. Personality and Individual Differences, $10,121-126$.

Eysenck, S. B. G. \& Kozeny, J. (1990). Cross-cultural comparisons of personality: Czech and English subjects. Studia Psychologica, 32, 255-259.

Eysenck, S. B. G. \& Lee, H. S. (1985). Cross-cultural study on the characteristics of personality dimensions: Korean and English. Korean Journal of Psychology, 5, 51-66.

Eysenck, S. B. G., Pakula, A. \& Gostautas, A. (1991). Standardisation of the EPQ for the adult population of Lithuania. Psihologiceskij Zurnal, 12, 83-89.

Eysenck, S. B. G. \& Tambs, K. (1990). Cross-cultural comparison of personality: Norway and England. Scandinavian Journal of Psychology, 3I, 191-197.

Fonseca, A. C., Eysenck, S. B. \& Simues, A. (1991). Um estudo intercultural da personalidade: comparacao de adultos portugueses e ingleses no EPQ. Revista Portuguesa Pedagogia, 25, 187-203.

Hanin, Y., Eysenck, S. B. G., Eysenck, H. J. \& Barrett, P. T. (1991). A cross-cultural study of personality: Russia and England. Personality and Individual Differences, 12, 265-273.

Sanderman, R., Eysenck, S. B. G. \& Arrindell, W. A. (1991). Cross-cultural comparisons of personality: The Netherlands and England. Psychological Reports, 69, 1091-1096. 